\title{
Deleuze y Derrida: diferencias divergentes
}

\author{
Deleuze and Derrida: diverging diferences
}

DIEGO ABADI

\begin{abstract}
Resumen: A causa de su pertenencia a una misma generación intelectual, y del interés compartido en ciertas problemáticas que dominaron el campo filosófico de su tiempo, las filosofías de Deleuze y Derrida se han podido considerar como cercanas o, cuanto menos, como afines. En el presente trabajo, sin embargo, nos proponemos negar esa semejanza, exhibiendo una serie de puntos a partir de los cuales ciertas divergencias radicales emergen. Para ello, desarrollaremos uno de los tópicos quizá paradigmáticos de ambas filosofías, a saber, el de la diferencia. Así, mostraremos cómo, a pesar de su aparente similitud, la différance derrideana y la diferent/ciación deleuziana son nociones que dan cuenta de una incompatibilidad filosófica profunda.
\end{abstract}

Palabras clave: Deleuze, Derrida, Diferencia, Filosofía francesa.

\begin{abstract}
Because of their common belonging to an intellectual generation, and the shared interest in a number of issues that dominated the philosophy of their time, the works of Deleuze and Derrida were usually considered to be close and, in some senses, similar. In the present paper, however, we intend to deny that resemblance, showing a number of points from which irresolvable divergences emerge. To do this, we will develop one of the topics that may be considered to define both philosophies, namely the problem of difference. Thus, we show how, in spite of its apparent similarity, Derrida's différance and Deleuze's different/ciation are notions that reflect a deep philosophical incompatibility.
\end{abstract}

Keywords: Deleuze, Derrida, Difference, French philosophy.

\section{Introducción}

Entre las obras de Gilles Deleuze y Jacques Derrida sobrevuela un aura de semejanza: la centralidad de la noción de diferencia, cierto retorno a Nietzsche como respuesta a una hegemonía totalizante del hegelianismo, una crítica pos-fundacional a los sistemas cerrados, la recuperación de la noción de acontecimiento, y algunos otros tópicos dan cuenta de esa sintonía. A causa de esas temáticas compartidas y de la cercanía generacional, se los agrupó, junto con Foucault, bajo las categorías de pos-estructuralismo o French Theory.

Fecha de recepción: 12/12/2014. Fecha de aceptación: 21/03/2015.

* Becario doctoral del Consejo Nacional de Investigaciones Científicas y Técnicas (CONICET) y la Universidad Nacional de San Martín. Realizando en la actualidad estudios doctorales sobre la obra de Gilles Deleuze en la Universidad de Buenos Aires y en la Université Paris 8. Publicaciones recientes: "El aporte algebraico de Galois a la teoría deleuziana de los problemas", Revista Ágora: Papeles de filosofía (en prensa); "El don y lo imposible. Figuras de lo cuasi-trascendental en Jacques Derrida', Contrastes. Revista Internacional de Filosofía, vol. XVIII (2013),pp.9-27. Mail: diego.abadi@gmail.com 
Pero a diferencia de lo acontecido con Foucault, a quien Derrida dirige un artículo crítico que desencadena un intercambio polémico entre ambos, y a quien Deleuze dedica un libro, que cierra una larga serie de textos y comentarios recíprocos, Derrida y Deleuze casi no dedicaron espacio en su obra publicada a analizar el pensamiento del otro. Entre sus textos puede deducirse una especie de indiferencia respetuosa, cuya huella se traduce en alusiones y comentarios al paso, siendo las más relevantes, por parte de Derrida, una nota al pie de "La différance" en la que se menciona una coincidencia con Deleuze alrededor del tema de la diferencia de fuerzas en Nietzsche, y por parte de Deleuze, un puñado de notas al pie de Diferencia y Repetición y El anti Edipo, apuntando sobre todo a "Freud y la escena de la escritura", y unas líneas en el cuerpo del texto de El anti Edipo. Allí, en apenas media página, se exponen tanto sus coincidencias con el concepto derrideano de escritura como su punto de disidencia, condensado en una sola oración. Pero a pesar de esa falta de materia textual, o quizá, podríamos decir, gracias a ella, la semejanza entre ambos pensamientos se mantuvo, de una manera implícita, como una tesis aceptada pero nunca del todo desarrollada. De hecho, así lo afirma el propio Derrida en el obituario que escribe tras la muerte de Deleuze:

Desde el principio, todos sus libros (pero sobre todo Nietzsche, Différence et Répétition, Logique du sens) fueron para mí no sólo fuertes incitaciones a pensar, por supuesto, sino que en cada ocasión la experiencia turbadora, tan turbadora, de una proximidad o de una afinidad casi completa con las "tesis", si puede decirse así, a través de las diferencias demasiado evidentes en aquello que llamaré, a falta de palabra mejor, el "gesto", la "estrategia", la "manera": de escribir, de hablar, de leer quizás. Por lo que respecta, aunque esta palabra no es apropiada, a las "tesis", y concretamente a aquella que concierne a una diferencia irreductible a la oposición dialéctica, una diferencia "más profunda" que una contradicción (Différence et Répétition), una diferencia en la afirmación felizmente repetida ("sí, sî́), la asunción del simulacro, Deleuze sigue siendo sin duda, a pesar de tantas diferencias, aquel de quien me he considerado siempre más cerca de entre todos los de esta "generación" (...) (Derrida, 1995).

Y es quizá esa misma línea la que sigue Jean-Luc Nancy en su artículo "Las diferencias paralelas. Deleuze y Derrida" (Nancy, 2008, 249-262). Nancy parte allí de lo que considera como su contemporaneidad, en tanto comunidad problemática compartida, y que identifica como "el tiempo del pensamiento de la diferencia" (Nancy, 2008, 250). Así, intentando ser fiel a aquel dictum, Nancy reconoce que hay entre ellos maneras diferentes de pensar la diferencia, pero postulando sin embargo que se trata de diferencias paralelas. Es decir, las diferencias ocuparían espacios heterogéneos, ni convergiendo para unificarse en una posición idéntica, ni divergiendo de modo de arribar una mutua exclusión. Sin embargo, Nancy aclara que no demostrará su propia tesis del paralelismo, contentándose simplemente con hacer un corto bosquejo que permita abrir el juego ${ }^{1}$. Despliega entonces

1 “(...) sólo quiero sugerir esto: su paralelismo. No lo demostraré (por lo demás, la existencia de paralelas entendidas en el sentido euclidiano es un axioma), no haré más que un corto bosquejo. Ni un estudio, ni un análisis. Me aligero de toda referencia, solamente abro el juego.” (Nancy, 2008, 253). 
un gesto ambiguo: borra por un lado la diferencia entre los dos, aludiendo a los autores como D y D, pero marca por otro el "hiato considerable" que considera se cierne sobre ambos a través de definiciones de los autores que parecen oponerse (Deleuze dirá "diferir consigo mismo", mientras que Derrida dirá "sí mismo difiréndose" (Nancy, 2008, 255), y en lo que respecta al sentido, por ejemplo, "uno lo ve diferir abriéndose, el otro lo ve ser abierto difiréndose" (Nancy, 2008, 256)). Pero la ambigüedad deliberada de Nancy confunde el pensamiento diferente de la diferencia con la mera imprecisión, en la medida en que, a través de la exposición de definiciones o juegos de palabras que parecen espejarse, intenta conciliar la heterogeneidad del paralelismo con la afirmación implícita de que sin embargo hay, entre las diferencias, una complementariedad que las asemeja.

En el presente texto nos proponemos entonces sostener lo contrario. Si bien aceptamos que ambos autores parten de temáticas compartidas, temáticas que de hecho conforman un campo problemático que los excede y comprende a muchos otros autores de gran relevancia, ${ }^{2}$ creemos sin embargo que aquella cercanía planteada no es más que aparente, habiendo entre ambos pensamientos una divergencia radical ${ }^{3}$. Ahora bien, en un primer momento hablamos de las obras de ambos autores, y posteriormente nos referimos a su "pensamiento". Evidentemente, en el espacio de un artículo sería imposible plantear una simple comparación entre las obras; como tampoco, con escaso margen para trazar matices y proveer el material textual necesario para sostenerlo, podría justificarse la exposición sin más del "pensamiento" o de un pensamiento en cada autor en cuestión. Por lo tanto, nos centraremos en la cuestión de la diferencia, y más precisamente, en las nociones particulares de diferencia que cada uno de los autores construye. Si bien no podremos delimitar el campo de aparición y despliegue de una noción semejante, nos proponemos sin embargo indicar a partir de qué problemáticas tales conceptos surgen en cada uno de los autores, qué funciones cumplen en el interior de cada obra, y cómo se relacionan con otras nociones que aquellas exigen o en las cuales pueden encontrarse posteriormente comprendidas.

En lo que respecta a la ubicación de la temática de la diferencia en cada una de las obras, habría que hacer ciertas precisiones. Si bien ocupa un lugar preponderante en las obras del primer período de producción tanto de Deleuze como de Derrida, posteriormente los conceptos de diferencia desarrollados por cada uno de ellos pierden protagonismo, dando lugar a otros conceptos o pasando a ser nombrados de otro modo, según las condiciones del problema enfocado. Pero en la medida en que se trata en ambos casos de una

2 En el prefacio a Diferencia y repetición, Deleuze resume su visión acerca de las problemáticas epocales compartidas: "El tema aquí tratado se encuentra, sin duda alguna, en la atmósfera de nuestro tiempo. Sus signos pueden ser detectados: la orientación cada vez más acentuada de Heidegger hacia una filosofía de la Diferencia ontológica; el ejercicio del estructuralismo (...). Todos estos signos pueden ser atribuidos a un anti-hegelianismo generalizado: la diferencia y la repetición ocuparon el lugar de lo idéntico y de lo negativo, de la identidad y de la contradicción. Pues la diferencia no implica lo negativo, y no admite ser llevada hasta la contradicción más que en la medida en que se continúe subordinándola a lo idéntico.” (Deleuze, 2002, 15).

3 En el campo de los comentadores de la obra de Deleuze, esta opinión es compartida, entre otros, por Gordon Bearn (Bearn, 2000) y Daniel Smith (Smith, 2012). Este último de hecho afirma: "This difference may appear to be slight, but its very slightness acts like a butterfly effect that propels Derrida and Deleuze along two divergent trajectories that become increasingly remote from each other, to the point of perhaps being incompatible" (Smith, 2012, 275). 
noción de gran relevancia, creemos que al mostrar sus avatares podremos también esbozar una mirada más general sobre el pensamiento de los autores que nos ocupan.

Nuestra exposición tendrá entonces la siguiente estructura. En un primer punto, con el fin de llegar a la noción de différance, partiremos del problema que creemos puede dar cierta unidad al pensamiento derrideano. Una vez hecho eso, podremos mostrar cómo el despliegue de dicho problema lo lleva a inaugurar un modo nuevo de pensar el signo representativo, dotándolo de un alcance cuasi-trascendental, lo que a su vez lo conduce a postular la noción de différance. Finalmente, para dar cuenta del destino de esta noción, exhibiremos sucintamente el reordenamiento al que Derrida somete sus nociones a partir de la década del ochenta, y la reintroducción de la trascendencia que esta reformulación implica. En un segundo punto, nos ocuparemos del pensamiento de Deleuze, aunque en este caso la exposición estará desde el inicio estructurada según una lógica del contrapunto. Partiremos entonces de la crítica que Deleuze dirige a la representación, e intentaremos mostrar cómo tras ésta se anuncia un pensamiento positivo de la diferencia. Marcaremos la distancia que hay entre este tipo de diferencia y la différance derrideana, e intentaremos responder a las objeciones que desde la segunda se podrían dirigir a la primera. Para ello, nos detendremos en la cuestión de la determinación, e intentaremos dar cuenta de la particular relación que la diferent/ciación deleuziana tiene con lo indeterminado. Por último, en una muy breve conclusión, intentaremos poner de relieve lo que creemos puede considerarse como un presupuesto de la filosofía derrideana, mencionando las consecuencias teóricas y prácticas que se desprenden de aquel.

Pero resulta necesario aclarar que si bien por momentos intentaremos plantear un contrapunto, nuestra exposición no adquirirá sin embargo la forma de una comparación neutral. En la medida en que rechazamos el axioma euclideano de Nancy, concebimos una divergencia que hace a ambas perspectivas incompatibles. En ese sentido, nos ubicaremos en la perspectiva deleuziana, ya que creemos que desde allí el pensamiento derrideano se encuentra más fielmente comprendido de lo que está el pensamiento de Deleuze desde la perspectiva de Derrida.

\section{Derrida}

\section{a) El proyecto deconstructivo}

El problema bajo el cual creemos que pueden organizarse los cuasi-conceptos derrideanos es el de la puesta en cuestión de la identidad o, quizá más precisamente, de los procesos identitarios. Es decir, si la crítica a las totalidades fue un problema que atravesó a muchos y variados autores en la segunda mitad del siglo XX, en Derrida esa preocupación deja de ser una preocupación política derivada -la preocupación por el totalitarismo como consecuencia de la postulación de totalidades-, para resonar en el interior mismo del discurso filosófico, reconociendo un movimiento propiamente conceptual que hace de la identidad una clausura sobre sí, y conlleva la postulación de una "interioridad" originaria y/o final.

Esta crítica se jugará en varios planos: por una parte, en un nivel hermenéutico, enfocándose en el discurso filosófico como objeto de lectura, por otro, en un nivel fenomenológico, dirigiéndose a cierto tipo de experiencia subjetiva. Dichos niveles, sin embargo, no son 
más que indicativos, y los introducimos por la utilidad que aportan a nuestra exposición, ya que Derrida se propondrá, por razones que veremos a continuación, difuminar esos límites, explotando la ambigüedad resultante de dicha operación. Partiendo entonces de esa distinción provisoria, en lo que respecta a la lectura de la disciplina filosófica, la deconstrucción se presenta como una empresa que si bien es crítica de la metafísica, no por eso anuncia ni aboga por su fin, ya que no dirige su ataque a la metafísica sin más, sino a un rasgo que históricamente parece haberla acompañado, pero cuya inherencia esencial habrá que poner en cuestión. A este respecto, el rasgo que define la totalización se traduce como una crítica al carácter de sistema cerrado del discurso filosófico. Y dentro de esta línea pueden a su vez separarse distintos niveles análogos de totalización, ya que serán diferentes casos de estructuras cerradas autosuficientes: el libro, como unidad mínima, la obra de un autor, en tanto sistema filosófico completo, y el discurso filosófico en general, verdadero portador del rasgo del que los anteriores son herederos. En "Tímpano", artículo que funciona como introducción a Márgenes de la filosofía, Derrida se enfoca en esto último, afirmando que la "filosofía siempre se ha atenido a esto: pensar su otro" (Derrida, 2003, 17-18), transformando así lo otro, lo exterior o lo no-filosófico, en $s u$ otro o $s u$ afuera, mediante un proceso de apropiación que lo incluye como momento propio de la filosofía. Así, le lectura deconstructiva se propone, en cada texto enfocado, encontrar el hilo a través del cual un libro o un sistema pierden la identidad que ellos mismos pretenden poseer y se abren hacia una alteridad que los desborda.

Pero ese movimiento de cierre sobre sí que caracteriza a los sistemas cerrados tiene como condición y como efecto la producción de un elemento peculiar, cuyos nombres varían según el caso, pero que definen siempre algún tipo de presencia, y que funcionan como origen y como telos. Si hay una voluntad de desmitificación en el pensamiento derrideano, esta se dirigirá, una y otra vez, a mostrar que esa presencia, que funciona como dadora de sentido, nunca es efectivamente dada en una experiencia presente, sino que no es más que el efecto retroactivo de alguna especie de re-presentación.

\section{b) Inversión del lugar del signo representativo}

Para captar la necesidad de aquella operación es preciso dejar a un lado la perspectiva hermenéutica y trabajar sobre el nivel fenomenológico. Para ello, las lecturas de Husserl que Derrida lleva adelante en sus primeros textos publicados resultan ejemplares. Podría decirse, parafraseando el subtítulo de La voz y el fenómeno, que allí el objetivo de Derrida es justamente introducir el problema del signo en la fenomenología de Husserl. Fiel a su proyecto cartesiano, éste último se propone acceder al verdadero núcleo de la subjetividad, a la conciencia vivida que será el principio de todos los principios. Para ello, en su camino de reducción, Husserl tendrá que deshacerse de todo aquel contenido de la conciencia que la ligue a lo empírico, y entre esos elementos estarán los signos. Así, divide los signos en indicativos y expresivos, los primeros como meras señales, y los segundos como signos portadores de sentido o querer-decir (Bedeutung). Pero la diferencia entre ambos tipos de signos no es exactamente la de ser o no lingüísticos, ya que los signos indicativos, aunque en un sentido derivado, también lo son. La distinción yace pues en el tipo de relación que poseen con el querer-decir: mientras que los signos indicativos mantienen con este una 
relación de mera exterioridad, los signos expresivos guardan con aquel una relación interior. Así es que, si bien toda expresión estaría de hecho en algún punto contaminada por signos indicativos, los signos expresivos estarían de derecho a resguardo de aquella a causa de su relación interior con el querer-decir. Pero esta relación no define todavía una identidad, ya que entre el signo expresivo y el querer-decir se encuentra el elemento de la voz, en tanto discurso oral no exteriorizado, recogido en una voz interior como monólogo puro. Éste, a su vez, remitiría a la consciencia voluntaria como querer-decir, la consciencia viviente presente a sí, que funcionaría como el principio de los principios. Así pues, a partir de la vivencia pura de la consciencia se deriva una primera representación, la de las palabras como signos expresivos en el monólogo interior, de la cual a su vez se deriva una segunda representación, la de las palabras reales o efectivas, que tienen una inscripción empírica.

Ahora bien, toda la carga de la demostración está puesta entonces en la vivencia presente a sí, que describe un instante como unidad indivisa del presente temporal, y absolutamente ajeno a la significación. Pero Derrida sostiene que, desde el propio texto husserliano, aquella esfera de presencia pura resulta insostenible:

Se apercibe uno entonces muy pronto de que la presencia del presente percibido no puede aparecer como tal más que en la medida en que compone continuamente con una no-presencia y una no-percepción, a saber, el recuerdo y la espera primarias (retención y protención) (...) si la puntualidad del instante es un mito, una metáfora espacial o mecánica, un concepto metafísico heredado, o todo eso a la vez, si el presente de la presencia a sí no es simple, si se constituye en una síntesis originaria e irreductible, entonces toda la argumentación de Husserl está amenazada en su principio. (Derrida, 1985, 114, 117-118).

Quizá resulta extraño identificar la retención y la protención como signos, pero allí hay una operación de lectura deliberada. Si un signo es aquello que representa o sustituye a alguna otra cosa que no se da en sí misma, la retención y la protención son de alguna manera las representaciones mínimas de la conciencia. Así, para Derrida, signo y representación se tornan equivalentes: ambas son el efecto, conservado o conservador, de una presentación. Y es justamente en este punto que Derrida realiza la operación de lectura que definirá su estilo filosófico, efectuando una redistribución de lo empírico y lo trascendental. Si tradicionalmente la metafísica pensó la presencia como primera, lógica o temporalmente, y por lo tanto como condición trascendental, y todas las formas de re-presentación o significación como formas empíricas derivadas de ésta, la puesta en cuestión de la presencia conduce a invertir aquella distribución. Así pues, en lugar de justificar la imposibilidad de hecho de acceder a una presencia para sostener de derecho su valor trascendente, Derrida postula que tal imposibilidad de la presencia a sí constituye una experiencia de derecho o trascendental, y no meramente su consecuencia empírica. Continuando con el comentario de Husserl, en el siguiente fragmento Derrida resume lo anterior e introduce nociones de las que nos ocuparemos a continuación:

la presencia del presente es pensada a partir del pliegue del retorno, del movimiento de la repetición y no a la inversa. Que este pliegue sea irreductible en la presencia 
o en la presencia a sí, que esta huella o esta diferancia [différance] sea siempre más vieja que la presencia, y le procure su apertura, ¿no prohíbe todo eso hablar de una simple identidad consigo mismo "im selben Augenblick”? (Derrida, 1985, 122).

Así, se produce una inversión en el camino de producción del sentido: ya no se trata de una presencia primera, que al ausentarse empíricamente, genera como efectos diversos tipos de signos -en este caso "pliegues del retorno" o "movimientos de la repetición"-, que a medida que se alejan de la fuente de sentido tienen una relación cada vez más exterior y más material con este, sino que por el contrario lo primero serían los signos y su posibilidad de repetición, inevitablemente materiales y exteriores, y la presencia, o los valores que se le asocian, sus efectos.

\section{c) Iterabilidad y différance}

El signo, tradicionalmente condicionado por la presencia de la cual es signo, deviene condición de posibilidad de una experiencia, imposible de derecho, de la presencia. Esto nos pone en el camino de una noción con la que Derrida se refiere a este particular tipo de repetición: la iterabilidad. Esta noción intenta ligar la repetición a la alteridad, en la medida en que, si la repetición es primera, no puede decirse que repita una presencia idéntica, sino que por el contrario, en el movimiento de su repetición diferenciante otorga cierta identidad relativa a lo repetido. Habíamos identificado anteriormente al signo con la representación por su común relación con la presencia. Ahora, dando cuenta de la potencia de repetición que estos poseen por sí mismos, puede verse cómo se despegan de una empiricidad bruta y se elevan hacia cierto carácter trascendental. De hecho, Derrida deja de lado nociones como signo o representación, en la medida en que ambas se encuentran demasiado asociadas a un valor de presencia que les da sentido -el significado en el caso del signo, la presentación en el caso de la representación-, y se vuelca a otros términos, como los de escritura o huella. Pero bajo dicha elección de términos se halla una operación conceptual de gran importancia: la generalización, o puesta en equivalencia, de todos los signos, y con ello, su consiguiente elevación a un estatuto cuasi-trascendental. Para dar cuenta de esa elevación, la escritura o la huella pasan a llamarse archi-escritura o archi-huella. Es esta generalización la que justifica nuestra prudencia inicial en el momento de hablar de diferentes niveles, hermenéuticos y fenomenológicos, de la lectura deconstructiva, ya que si la huella es una estructura que atraviesa transversalmente todos los niveles de la experiencia, torna equívocas y siempre provisorias las distinciones entre campos de acción.

Pero el esbozo de esa especie de campo trascendental de signos hace surgir cuestiones esenciales: ¿puede decirse que la huella sea entonces un trascendental? ¿Hay efectivamente una inversión de lo empírico y lo trascendental? Como una suerte de respuesta a esos interrogantes aparece la noción de différance. Esta noción retoma, y se propone profundizar, la lógica de la iterabilidad, proveyendo cierto principio de funcionamiento a aquellas repeticiones de la diferencia o de la alteridad. Dice Derrida al respecto:

En una conceptualidad y con exigencias clásicas, se diría que la "diferancia" [différance] designa la causalidad constituyente, productiva y originaria, el proceso de 
ruptura y de división cuyos diferentes o diferencias serían productos o efectos constituidos. Pero aproximándonos al núcleo infinitivo y activo del diferir, "diferancia" (con a) neutraliza lo que denota el infinitivo como simplemente activo (...). Y veremos por qué lo que se deja designar como diferancia [différance] no es simplemente activo ni simplemente pasivo, y anuncia o recuerda más bien algo como la voz media, dice una operación que no es una operación, que no se deja pensar ni como pasión ni como acción de un sujeto sobre un objeto (...). (Derrida, 2003, 44).

Detengámonos pues sobre las dos indicaciones que Derrida provee en este extracto. Si bien aclara que corresponde a una conceptualidad clásica que se pretende cuestionar, la definición dada nos permite acercarnos a uno de los rasgos característicos de la différance, es decir, al de "causalidad constituyente, productiva y originaria". Así, la différance da lugar a un diferir que posee un sentido doble: diferir en tanto temporización y en tanto espaciamiento. El primero de ellos recoge el matiz temporal que se halla en el diferir en tanto "dejar para más tarde", comprendiéndolo como la mediación temporal "que suspende el cumplimiento o la satisfacción del 'deseo' o de la “voluntad"' (Derrida, 2003, 43). El segundo de ellos recoge al sentido más coloquial del diferir en tanto "no ser idéntico, ser otro" (Derrida, 2003,44), y refiere a la producción de una cierta distancia polémica entre lo que difiere. Así, la différance es aquello que hace que los diferentes difieran espacio-temporalmente, sosteniendo la duración de cada diferencia a través de una repetición diferenciante que posterga el cumplimiento de una presencia (inadecuación consigo), y manteniendo unas fuera de las otras a las diferencias entre sí (inadecuación entre sí).

Ahora bien, tal como advertía Derrida, la designación de la différance como "causalidad constituyente" formaba parte de una perspectiva tradicional que resultaba necesario deconstruir. Ya que si siguiéramos la senda marcada por esa definición llegaríamos a las preguntas “QQué es lo que difiere? ¿Quién difiere? ¿Qué es la différance?” (Derrida, 2003, 50), que Derrida considera mal planteadas, en la medida en que implican comprender a la différance como "existente-presente" (Derrida, 2003, 50). Derrida no se refiere a la différance como a una causa incondicionada o como puro principio productivo, ya que cree que ello conduce inevitablemente a la postulación de un ente presente, lógica o temporalmente primero, y a la consiguiente reconstrucción de la criticada lógica de la presencia y la representación. La noción de différance se hace entonces elusiva y difícil de aprehender, ya que debe referirse tanto al diferir espacio-temporal en tanto efecto como al diferir espacio-temporal en tanto causa. O, según el estilo derrideano, podría decirse que no puede referirse ni a uno ni al otro, ya que puesto en cuestión el fundamento en tanto ente trascendente, el intento por trazar una distinción acabada entre el diferir como fundado y el diferir como fundamento resultará vana.

Cabe a su vez recalcar que la imposibilidad de designar un fundamento presente no equivale a postular la ausencia como fundamento, ya que aquella operación sigue asegurando el lugar incontaminado de lo trascendente. Así pues, no puede hablarse de una falta en el origen, pero sí habría que postular una inadecuación originaria entre originario y derivado. Ello implica dos hipótesis que trabajan a la par según una lógica aporética: la de un incondicionado excesivo, siendo las condiciones las repeticiones que tornan experimentable aquel exceso; y la de un incondicionado ausente, siendo las condiciones los efectos repetidos que 
retroactivamente dan cuerpo a aquella ausencia. La apuesta teórica derrideana yace pues en la afirmación de esta tensión aporética, que tornando imposible la identificación totalizante intenta cumplir el designio crítico planteado. Así pues, différance es uno de los tantos nombres que se le dan a la estructura cuasi-trascendental que, sin un centro o una presencia, da lugar a -y se confunde con- los existentes diferentes, conminándolos a diferir espaciotemporalmente sin un telos que organice su recorrido.

\section{d) La estructura formal: condiciones de imposibilidad de la experiencia}

Pero si la différance designaba una estructura cuasi-trascendental, en la cual fundamento y fundado resultaban indistinguibles, a partir de los trabajos que se desarrollan de 1980 en adelante, Derrida se propone, aun afirmando su imposibilidad de distinción de hecho, volver a separar al menos de derecho esos niveles. Esta operación teórica podría parecer paradójica, pero responde a una necesidad doble, que por un lado corrige y por otro profundiza los desarrollos anteriores.

Una de las caras de aquella necesidad resulta de un cuestionamiento de tipo ético; más precisamente, de la acusación de relativismo ético que se le hizo a la deconstrucción. Así pues, en su conferencia "Del derecho a la justicia", a propósito de problemáticas políticas, Derrida traza una distinción entre un plano incondicionado y un plano condicionado, dando una determinación positiva del primero como justicia y una del segundo como derecho. Pero en la medida en que la imposibilidad de designar un fundamento trascendente sigue siendo un condicionamiento ineludible, Derrida intenta conciliar esa distinción de derecho con un funcionamiento dinámico que vuelve a contaminarlos estructuralmente. Así pues, en este caso, la justicia funciona como condición de posibilidad del derecho, en la medida en que, en tanto "infinita, incalculable, rebelde a la regla" (Derrida, 2008, 50), plantea un imperativo que da nacimiento al derecho, pero es a la vez su condición de imposibilidad, en la medida en que, en tanto infinita, singular e incalculable, conmina al derecho a una realización imposible, en tanto este se comprende esencialmente como institución de reglas finitas y calculadas. Pero, recuperando la aporía o el double bind planteado en la sección anterior, la misma dinámica puede pensarse en un sentido inverso: el derecho es la condición de posibilidad de la justicia, ya que sin la fuerza de un cálculo, la justicia nunca podría adquirir efectividad, pero es a la vez también su condición de imposibilidad, ya que, tal como lo mencionamos anteriormente, el derecho inscribe a la justicia en un cálculo general que inevitablemente traiciona su singularidad.

Pero si bien esta problemática del derecho y de la justicia parece referirse exclusivamente al ámbito limitado de las categorías políticas, la estructura de doble vínculo que las relaciona va a exceder ese campo particular para transformarse en lo que Derrida denominará una "estructura universal de la experiencia" (Derrida, 2002, 289). Así pues, los nombres de lo incondicionado podrán variar indefinidamente (el Otro, el acontecimiento, el don), requiriendo ser puestos en relación con un condicionado para determinarse, aunque siempre parcialmente. Lo que no variará será entonces la estructura de funcionamiento que liga a uno con el otro, y que terminará de definir lo cuasi-trascendental como las condiciones de posibilidad de la experiencia que son, en sí mismas, también sus condiciones de imposibilidad. 
Ello nos permite abordar la otra cara de la necesidad de este reordenamiento. La ampliación del campo trascendental efectuada mediante la postulación de nociones como la archi-huella, y la imposibilidad de distinción entre los niveles de lo incondicionado y lo condicionado que movilizaba, por ejemplo, la noción de différance, corrían el riesgo de generar un efecto paradójico: las huellas, mediante la borradura del origen, parecerían cerrarse sobre sí mismas, habilitando la construcción de un adentro omniabarcativo, en lugar de propiciar la apertura hacia un afuera que pudiese conectar con una alteridad radical. Para evitar pues la posibilidad de una clausura sobre sí, Derrida recupera la trascendencia levinasiana y, en lugar de suspender su identificación con un origen o un telos, hace de esta, positivamente, origen y telos, sólo que al precio de concebirlos como imposibles. Así pues, la noción de différance, que intentaba expresar la diferencia espacio-temporal y la diferencia entre originario y derivado, deja su lugar a una estructura formal de la experiencia y a otro tipo de nombres, que se referirán a lo incondicionado o a lo imposible. Si el proyecto derrideano partía entonces de la crítica de la identidad y de los procesos identitarios que se le asociaban, la noción de alteridad probará ser más efectiva que la noción de diferencia a la hora de pensar la cuestión de la no-identidad.

\section{Deleuze}

\section{a) Diferencia en sí y crítica de la representación}

Tal como lo hemos visto, Derrida inicia su decurso argumentativo denunciando el valor de la presencia como mistificación. Podría en ese sentido decirse que, al impugnar dicho valor como origen de todo tipo de representación, libera a esta última de su carácter derivado, haciéndola florecer en un plano de condicionamiento en el que todos los signos se tornan equivalentes, y que no puede denominarse, a causa de la pérdida de la presencia como valor ordenador trascendente, ni como empírico ni como trascendental. Así pues, a partir de la falla de la representación, es decir, del reconocimiento de su inevitable inadecuación, se suspende la afirmación ontológica, comprendiéndose esta como la predicación positiva y definitiva sobre aquel incondicionado que funcionara como origen de las representaciones.

Deleuze, en cambio, desarrolla una operación opuesta, ya que apunta sus críticas explícitamente a la representación, intentando liberar una nueva noción de presencia o presentación que se desligue de una relación de inherencia con la representación. En Diferencia y repetición, libro publicado en el mismo año en que tuvo lugar la conferencia sobre la differance de Derrida, se desplegará esta doble operación, mediante un rechazo de la representación y de la lógica que implica, y en favor del pensamiento de un tipo de presencia que, en tanto "presentaciones de la diferencia" (Deleuze, 2002, 223), difícilmente pueda equipararse a la de un ente presente.

Es por ello entonces que la representación es el blanco de las críticas deleuzianas no exclusivamente por lo que se podría considerar como sus fallas o sus limitaciones, sino también por las consecuencias que su correcto funcionamiento implica. La representación da cuenta de una configuración general del saber que, heredera de una ya olvidada decisión moral, somete la diferencia pura a la identidad. Así pues, mediante la identidad 
en el concepto ${ }^{4}$ la analogía en el juicio, la oposición en los predicados y la semejanza en la percepción, toda diferencia individual queda inevitablemente reducida a una semejanza previa. En el éxito de la representación, el pensamiento adquiere una imagen absolutamente pueril: el pensar se agota en el reconocimiento de objetos, a través del ejercicio armonioso de las facultades que, bajo la identidad de un sujeto como concepto indeterminado, forman un sentido común. Así, pensar se identifica con la predicación más elemental, "S es P", y su negativo, con el error como fruto de un mal reconocimiento, decir "buen día, Teodoro" cuando el que pasa es Teeteto (Deleuze, 2002, 228). Es pues, como consecuencia de su mismo funcionamiento, que al pensar la diferencia, y su noción asociada de repetición, la representación se precipita en antinomias de las cuales no puede librarse. Si el concepto se entiende como la unidad de un múltiple, no hay manera de superar la abstracción: tanto la diferencia como la repetición se tornan inaprehensibles. En cuanto a la diferencia, la representación sólo puede pensarla como diferencia en el concepto. Es decir, en tanto diferencia conceptual, la diferencia se torna diferencia específica y asegura, mediante la oposición en los predicados, la especificación del concepto. Pero la especificación tiene un límite claro, que es el de individuo, de tal manera que la diferencia nunca puede llegar hasta la diferencia individual, cayendo la presencia singular irremediablemente fuera del concepto. Por esa razón, desde esta perspectiva, la noción de repetición se torna necesaria, ya que, en tanto diferencia sin concepto, recoge aquella parte de la diferencia que el concepto no podía retener. Lo repetido será entonces aquello que difiere sin concepto, es decir, aquello que sólo se distingue in numero, espacio-temporalmente.

Retomando entonces la comparación, si bien para ambos autores la representación reviste un problema, la resolución de dicho problema traza vías divergentes. Si, tras reconocer una especie de inadecuación estructural, Derrida libera a la representación de la presencia, podría decirse que Deleuze invierte la carga de la prueba, forzando un cambio de perspectiva. Así pues, si la representación falla, y es víctima de una inadecuación irresoluble, en lugar de denunciar a la noción de presencia que supuestamente la funda y mantener sin embargo los "derechos" de la representación como lo fundado, Deleuze, al desentenderse de aquel mismo valor de presencia, deja caer también a la lógica representativa que resultaba dependiente de aquel. Así pues, concebir al movimiento de la diferencia y de la repetición como ligado a una inadecuación entre originario y derivado es pensar la diferencia desde el punto de vista de la representación, conduciéndola a una perspectiva que, según lo ya expuesto, la torna impensable. Dejando entonces atrás las categorías de la representación y su funcionamiento predicativo, Deleuze puede ensayar una afirmación ontológica: hay un en sí de la diferencia, y hay un para sí que es la repetición. El devenir, como relación entre la diferencia y la repetición, será pues una disimetría en el origen, y no una inadecuación entre el origen y sus efectos.

4 En Diferencia y repetición Deleuze opone concepto, término que mantiene para referirse a la noción representativa que pretende criticar, al término Idea, que es aquel que refiere a su propia noción de multiplicidad. Más adelante en su obra, y más precisamente en ¿Qué es la filosofía?, el término concepto retoma el lugar que antes había ocupado el término Idea. Nosotros sin embargo mantenemos la distinción entre ellos, por una parte, porque en nuestra argumentación seguimos generalmente las líneas rectoras de Diferencia y repetición, y por otra, porque esa distinción resulta provechosa en la comparación con Derrida, sosteniéndose en ambos casos un rechazo del concepto, y una búsqueda de una noción alternativa como la de cuasi-concepto en uno, e Idea en el otro. 
En lo que respecta a la noción de signo, la diferencia entre ambos también se profundiza. Si para Derrida todos los signos se tornaban inevitablemente representativos, para Deleuze el signo se separa radicalmente de la representación. El signo será, para este último, una presentación, y por lo tanto, el objeto de un encuentro. Pero lo que se presenta a la sensibilidad es una disparidad - una diferencia de intensidad-, que en ningún momento se subsume bajo un concepto idéntico que la mediatiza, sino que comunica un movimiento que conecta las facultades en un para-sentido. Es decir, en lugar de que una diferencia se mediatice bajo el ejercicio conjunto de las facultades en un sentido común, y que así se reconozca un objeto como uno y el mismo sin importar la facultad desde la que se lo enfoque, la diferencia de intensidad fuerza a la sensibilidad a ir más allá de sí misma, llevando a su exceso a cada una de las facultades y dando lugar a una repetición de la diferencia, una repetición diferente de la diferencia, que refiere a un proceso de aprendizaje en lugar de designar el producto de un saber.

\section{b) Univocidad e inmanencia}

La afirmación ontológica deleuziana, la postulación de un en sí de la diferencia, permite a Deleuze llevar al pensamiento hacia zonas que, desde la óptica derrideana, se encontraban vedadas. Así pues, la diferencia se revela como un principio genético:

La diferencia no es lo diverso. Lo diverso es dado. Pero la diferencia es aquello por lo que lo dado es dado. Es aquello por lo que lo dado es dado como diverso. La diferencia no es el fenómeno, sino el más cercano noúmeno del fenómeno. (...) Todo fenómeno remite a una desigualdad que lo condiciona. Toda diversidad, todo cambio remiten a una diferencia que es su razón suficiente. Todo lo que pasa y aparece es correlativo de órdenes de diferencias, diferencia de nivel, diferencia de temperatura, de presión, de tensión, de potencial, diferencia de intensidad. (Deleuze, 2002, 333).

Pero si Derrida se negaba a definir a lo incondicionado como origen o fuente, lo hacía bajo el presupuesto de que ello implicaba transformarlo en un fundamento trascendente presente a sí. Si dividimos este sintagma complejo de modo analítico, tras haber visto porqué la diferencia no resulta equivalente a una presencia a sí, habría todavía que mostrar porqué tampoco puede equiparársela con un fundamento trascendente. Así, para abordar las categorías de "fundamento" y de "trascendencia", nos referiremos a dos nociones, las de causa inmanente y la de univocidad, que sirven para caracterizar el plano de las diferencias puras.

En lo que respecta pues al carácter trascendente del fundamento, recurriremos a la noción de causa inmanente que Deleuze expone en su lectura de Spinoza. En Spinoza y el problema de la expresión, al momento de presentar distintas relaciones causales posibles entre el fundamento y lo fundado, se distinguen tres tipos de causalidad: la causalidad creativa, la causalidad emanativa y la causalidad inmanente. La causalidad creativa, que se asocia con el pensamiento cristiano, plantea una separación radical entre la causa primera, Dios, y sus criaturas. El modo de causación es vertical, por donación, siendo la causa primera el ente ejemplar. Pero la causalidad emanativa -cuya formulación es obra de los 
neoplatónicos- y la causalidad inmanente -muchas veces insinuada pero nunca desarrollada completamente hasta la obra de Spinoza- tienen un rasgo común: ambas permanecen en sí para producir. Sin embargo, si bien la causa emanativa "permanece en sí, el efecto producido no es en ella y no permanece en ella" (Deleuze, 1996, 167), siendo que "el Uno es necesariamente superior a sus dones", ya que "no hay participación sino por un principio él mismo imparticipable, pero que da de participar" (Deleuze, 1996, 166). En el caso de la causa inmanente, en cambio "el efecto mismo es 'inmanado' en la causa en vez de emanar de ella. Lo que define la causa inmanente, es que el efecto está en ella, sin duda como en otra cosa, pero está y permanece en ella" (Deleuze, 1996, 167). Así, pues, si la diferencia en sí se plantea como inmanente, no tiene porqué asociarse necesariamente, en tanto principio genético, con un ente trascendente.

Pero para sostener la inmanencia, es imprescindible que esta no se comprenda, en ningún nivel, como inmanente $a$ algo. Si ello sucediera, las diferencias se transformarían en diferencias de algo, reconstruyendo así un fundamento idéntico, dentro del cual las diferencias no serían más que identidades parciales. Cabe preguntarse entonces: ¿cómo mantenerse en el pensamiento de la pura diferencia? ¿Cómo plantear un plano de diferencias que no remitan a nada exterior a ellas? Para ello, Deleuze responde, es preciso dejar atrás el fundamento y pasar al universal desfondamiento. Es con ese propósito que Deleuze recupera y reinventa la noción de univocidad del ser. Así, afirmará, para pensar las puras diferencias es necesario pensar el ser como unívoco, pero el ser se dirá en un único y mismo sentido sólo a condición de decirse de lo diferente. Así pues, las diferencias componen la univocidad, o la pura inmanencia, del ser. Nada trasciende al ser unívoco que, en tanto afuera absoluto, no puede nunca cerrarse sobre sí de modo de reconstruir un fundamento. El ser unívoco, lo indeterminado o la pura inmanencia, no es entonces un fundamento, sino que debe ser, por el contrario un desfundamento universal.

\section{c) La determinación de lo indeterminado}

Pero si bien las aclaraciones anteriores respondían a una objeción externa que podía hacerse desde la posición de Derrida, todavía es necesario resolver una cuestión que hace a la posibilidad misma de sostener a la diferencia como pura inmanencia. Al plantear la causa inmanente como origen productivo, quedaron distinguidos, por un lado, las puras diferencias indeterminadas como elementos últimos sin forma ni función, y por otro, los entes actuales como objetos determinados. Ahora bien, si no se logra pensar la relación que hay entre un plano y el otro, mostrando en qué sentido el primero es principio genético del segundo, la inmanencia, en tanto mero indeterminado, será otra vez equivalente a una trascendencia, separada de sus productos o efectos. En este punto la divergencia entre Deleuze y Derrida se hace patente. En el caso de Derrida, la puesta en cuestión del fundamento generaba una crisis de determinación, porque al estar la mediación desligada de un fundamento, y manteniendo una relación equívoca con la trascendencia formal, se tornaba indeterminable. Si en Hegel la negatividad funcionaba como determinación debido al fundamento totalizante dentro del cual la diferencia se transformaba en contradicción, y en Kant, bajo el fundamento del sujeto trascendental las categorías brindaban una determinación formal como condiciones de posibilidad, en Derrida las condiciones 
de posibilidad, que son en sí mismas también condiciones de imposibilidad, ni subjetivas ni ontológicas, no pueden aportar más que una mediación indeterminada. En el discurso deconstructivo sobrevuela por tanto cierta equivocidad entre todos los tipos de signos, sin que haya forma de distinguir órdenes o jerarquías de determinación.

Deleuze, a diferencia de Kant, se propone despejar las condiciones reales o genéticas de la experiencia, y a diferencia de Hegel, necesita hacerlo sin recurrir ni a la negatividad ni a un fundamento Idéntico. Así pues, es preciso mantener a lo indeterminado -el desfundamento-, y producir un modo de determinación diferencial -no negativo-. Dice Deleuze al respecto:

La diferencia es ese estado en el cual puede hablarse de LA determinación. La diferencia "entre" dos cosas es solamente empírica, y las determinaciones correspondientes, extrínsecas. Pero, en lugar de una cosa que se distingue de otra, imaginemos algo que se distingue -y que, sin embargo, aquello de lo cual se distingue no se distingue de él-. El relámpago, por ejemplo, se distingue del cielo negro, pero debe arrastrarlo consigo, como si se distinguiese de lo que no se distingue. (...) La diferencia es ese estado de la determinación como distinción unilateral. Acerca de la diferencia hay, pues, que decir que uno la hace, o que ella se hace, como en la expresión "hacer la diferencia". (Deleuze, 2002, 61) 5 .

Así pues, para dar cuenta del paso de lo indeterminado a la determinación, y para mostrar a qué se refiere cuando habla de hacerse de la diferencia, Deleuze construye la noción de diferent/ciación. Ni lo indeterminado es entonces un defecto del concepto, ni la determinación una mediación conceptual que lo niegue o lo limite, sino que se trata de un proceso sub-representativo de producción de diferencias individuales. Lo indeterminado se determina individuándose o actualizándose, y la individuación se lleva a cabo a través de un proceso de diferent/ciación mediante el cual, sin mediación alguna de un término idéntico ni bajo condiciones mínimas de semejanza, las diferencias se relacionan unas con otras conformando sistemas diferenciales. Resulta necesario distinguir entonces tres niveles. En primer lugar, el de las puras diferencias como origen indeterminado. En tanto pura inmanencia o ser unívoco, estas conforman un caosmos, un plano compuesto por divergencias en el que no todo está individuado. En segundo lugar, el nivel de lo virtual, donde tiene lugar la primera mitad del proceso de diferent/ciacion, la diferentiación. Si las diferencias puras son indeterminadas, en sus relaciones sin embargo se produce un tipo de determinación problemático-ideal, el de las relaciones diferenciales. Estas constituyen las condiciones problemáticas y pre-individuales, el campo problemático diferentiado sobre

5 Moises Barroso Ramos reemplaza el ejemplo del relámpago por el de las corrientes marinas, que creemos ilustra de un modo más intuitivo lo que se quiere mostrar: "Una corriente marina se distingue del océano porque la corriente tiene una individualidad, pero el océano no se distingue de la corriente, sino que la acompaña, como diferencia de su diferir, como multiplicidad diferencial. En realidad, en relación con esa multiplicidad diferencial, en relación con el océano infinito de la sustancia inmanente, las diferencias formadas no son nada, las corrientes no son nada o, más bien, sólo son singularidades, flujos heterogéneos en movimiento que coexisten en la multiplicidad intensiva, por más que podamos darles nombre: corriente del Golfo, de Canarias, Labrador, Falkland. Las corrientes son circuitos de intensidad en el océano, pero el océano es la multiplicidad intensiva de todos los circuitos." (Barroso Ramos, 2002, 60). 
el cuál se trazarán los casos de solución actuales. Es pues justamente lo actual o lo individuado lo que compone el tercer nivel mencionado, y es el proceso de diferenciación el que, mediante la creación de nuevos casos de solución, da lugar a la individuación. Pero si bien separamos tres niveles que parecen ser autónomos y tener una distribución lógicotemporal fija, se trata sin embargo de un único proceso de diferent/ciación, en el cual no se va de lo indeterminado a la diferenciación de un modo sucesivo y lineal. Habría que decir entonces que, en la medida en que no son fundamento, las puras diferencias no están en un plano originario anterior a los otros dos, sino que están entre el plano de lo virtual y el plano de lo actual, como el diferenciante de la diferencia, la diferencia que conecta las dos partes del proceso de diferent/ciación.

\section{Conclusión: un presupuesto derrideano}

Pero si en el apartado anterior intentamos poner a prueba las nociones deleuzianas, confrontándolas a lo que creíamos podían ser objeciones dirigidas desde la perspectiva derrideana, para terminar nos interesaría llevar adelante la operación opuesta, exponiendo una cuestión que compete al problema de la mediación y en la cual, desde un ángulo deleuziano, puede reconocerse un presupuesto implícito.

La pregunta que podría hacérsele a Derrida al respecto es: ¿por qué lo incondicionado necesita ser mediado? En el funcionamiento de las condiciones de posibilidad e imposibilidad que habíamos esbozado, esta necesidad se expresaba al postular que lo condicionado era también, por su parte, condición de posibilidad de lo incondicionado. Pero si lo incondicionado requiere de una mediación externa es porque Derrida concibe, de un modo más o menos explícito, al sin-fondo de lo incondicionado como a un puro caos. Así pues, en tanto apertura absoluta de lo diferente, lo incondicionado sería el abismo en el que toda diferencia se extingue. Y esto puede verse justamente en su lectura de Hegel cuando, tras identificar al Espíritu en su aparición indeterminada como "pura luz, simple determinabilidad, medio puro, transparencia etérea de la manifestación donde nada aparece más que el aparecer, la luz pura del sol" (Derrida, 1974, 265 A), afirma que entre aquella pura luz y el incendio no hay diferenciación posible: "Juego y pura diferencia, he ahí el secreto de un quema-todo [brûle-tout] imperceptible, el torrente de fuego que se abrasa a sí mismo" (Derrida, 1974, 266 A).

Deleuze, en cambio, considera que plantear que más allá del concepto hay un caos indiferenciado es la consecuencia de someterse a las exigencias de la representación para pensar aquello que de hecho escapa a su órbita:

Para la representación, es preciso que toda individualidad sea personal [Je], y toda singularidad, individual [Moi]. Allí donde se cesa de decir Yo [Je], también cesa por consiguiente la individuación, y allí donde la individuación cesa, cesa también toda singularidad posible. Es forzoso, desde ese momento, que el sin fondo se represente desprovisto de toda diferencia, ya que no tiene individualidad ni singularidad. (...) Del mismo modo que la individuación como diferencia individuante es un anti-Yo [Je], un anti-yo [moi], la singularidad como determinación diferencial es preindividual. El mundo del SE, o de "ellos", es un mundo de individuaciones impersonales y 
de singularidades preindividuales, que no se reduce a la banalidad cotidiana (...). La ilusión límite, la ilusión exterior a la representación, que resulta de todas las ilusiones internas, es que el sin fondo no tenga diferencia, cuando, en verdad, ella hormiguea en él. (Deleuze, 2002, 408-409).

Así pues, en lugar de plantear una instancia externa de mediación que oscila entre la limitación y la negación de lo incondicionado, Deleuze postula un proceso de diferent/ ciación mediante el cual, atravesando distintas fases, lo indeterminado mismo se diferencia hasta llegar a la constitución de diferencias individuales.

Pero este presupuesto derrideano tiene un alcance que excede lo meramente especulativo. Así, la aporía teórica que Derrida intentaba afirmar mediante su dialéctica de las condiciones de posibilidad imposibles tiene una deriva práctica muy marcada. Si la imposibilidad de un acceso teórico inmediato a lo incondicionado conducía a la aceptación de una inevitable mediación, desde la perspectiva práctica aquella aceptación se ve reforzada, ya que allí la mediación no es más solamente lo inevitable, sino que se transforma en algo deseable. Ante un incondicionado que es un caos indiferenciado, ante la pureza de un ser que es también pura violencia, en la mediación estará la clave de una nueva salud. Desde la perspectiva deleuziana, sin embargo, llegar a desear la mediación será el síntoma último de una incapacidad de afirmación. Un pensamiento que postule la limitación o la negación de la intensidad del ser con el pretexto de su autoconservación, y que eleve la espera y la pasividad a caracteres éticos privilegiados, difícilmente logre afirmar el devenir, y con él, la aparición de lo nuevo.

\section{Bibliografía}

Barroso Ramos, M. (2006), Inmanencia, virtualidad y devenir en Gilles Deleuze. Universidad de La Laguna. http://dialnet.unirioja.es/servlet/oaites? codigo=966.

Bearn, G. (2000), "Differentiating Derrida and Deleuze". Continental Philosophy Review 33: 441-465.

Deleuze, G. (2002), Diferencia y repetición. Buenos Aires, Amorrortu.

Deleuze, G. (1996), Spinoza y el problema de la expresión. Barcelona, Muchnik editores.

Derrida, J. (1974), Glas. Paris, Galilée.

Derrida, J. (1995), Tendré que errar sólo. Derrida en Castellano. www.jacquesderrida.com.ar

Derrida, J. (2003), Márgenes de la filosofía. Madrid, Cátedra.

Derrida, J. (1985), La voz y el fenómeno. Valencia, Pre-textos.

Derrida, J. (2008), Fuerza de ley. El "fundamento místico de la autoridad”. Madrid, Tecnos.

Derrida, J. (2002), Marx e hijos. En Demarcaciones espectrales. En torno a Espectros de Marx, de Jacques Derrida, ed. Michael Sprinker, 247-306. Madrid, Akal.

Nancy, J. L. (2008), Las diferencias paralelas. Deleuze y Derrida. En Por amor a Derrida, ed. Mónica B. Cragnolini, 249-262. Buenos Aires, La Cebra.

Smith, D. (2012), Essays on Deleuze. Edinburgh, Edinburgh University Press. 